\title{
Passive Façade Retrofit in War-Affected Dwellings in Syria
}

\author{
Walaa Haj Ali ${ }^{1}$, Ola Uduku \\ ${ }^{1}$ Manchester School of Architecture, Manchester, UK \\ Walaa.haj-ali@stu.mmu.ac.uk \\ ${ }^{2}$ Manchester School of Architecture, Manchester, UK \\ O.uduku@mmu.ac.uk
}

\begin{abstract}
The large-scale destruction of infrastructure in Syria has created a vast number of cross sector challenges including housing and energy. When surveying the range of buildings damaged due to the ongoing conflict in Syria, housing is by far the most affected sector with $65 \%$ of the estimated damage. Most major Syrian cities however have been damaged drastically though not completely destroyed. This raises the possibility of buildings to be refurbished. The aim of the study is to investigate the potential of energy performance of optimizing façade retrofitting strategies in the buildings affected by the Syrian war. While focusing on a typical residential building in Damascus Outskirts, the study targeted moderately damaged with limited damage observed to 5\%-30\% damage of the building structure. Decision-making in the selection of retrofit scenarios was a result of conducting three stages of vulnerability to measure damage and evaluate the scale of needed intervention. Based on the vulnerability assessment, multiple retrofit scenarios were developed to improve the building performance by two main objectives, Thermal comfort and energy loads. Multiple parameters, including wall materials, levels and types of insulation were tested to explore its influence on thermal comfort and energy loads including the effect of building materials, levels and types of insulation. The results of thermal simulation showed that the choice of insulated bricks for envelope is the optimum solution since insulated Brick envelope can significantly reduce heating and cooling loads by $40 \%$ in comparison to typical insulated concrete wall construction. However, the study recommended there is no optimal solution for approaching façade retrofit cases because selection criteria are associated to external economic and social factors such as implementation costs, inflation or privacy.
\end{abstract}

Keywords: façade retrofit, post-war retrofit, Syria, low energy retrofit, thermal comfort.

\section{Introduction}

The large-scale destruction in Syria has created a vast number of cross sector challenges including housing and energy. First, the damage to energy infrastructure including oil, natural gas pipelines and electricity networks made supplying fuel oil very challenging. Syria Energy statistics shows a massive gap between energy demand and energy supply [1]. Energy production decreased drastically since the conflict started, as it dropped by $90 \%$ as it was in 2011 [2]. Second, Housing is by far the most affected sector comparing to agriculture, health, education, energy and transport with $65 \%$ of the estimated damages [3]. However, this huge estimation of detected damaged structures are assigned different level of damage. UNOSAT [4] has conducted a comprehensive damage assessment of Syrian cities using satellite imagery captured between 2013 and 2017. Severity is calculated based on density of damaged infrastructure and weighted by a scale of damage. Huge number of housing stocks are moderately damaged, where the structure is still existed, but housing retrofit is needed. It is estimated that $37 \%$ of buildings have moderate damage. Aleppo and Damascus come in the first place in number of moderately damaged structures with around $25 \%$ of the total count of damaged structures [4]. The World bank in his Handbook for Reconstruction after Natural Disaster [5] states that programs of repairing and retrofitting can save many partially damaged houses can have a decisive impact on improving the reconstruction process in terms of cost, environmental impact, speed, supply of resources and community participation. Hence, moderately damaged dwellings retrofit provides an immediate response to the housing crisis in Syria. However, considering the current efficiencies in energy use and the ongoing energy crisis, housing restoration to the previous situation create a new barrier to having an adequate comfortable indoor environment. This paper investigates the potential of improving energy performance of façade retrofitting strategies in the 
moderate-damaged dwellings affected by the Syrian war. It intends to investigate the interaction of thermal performance while considering the thermal comfort in order to develop a framework for energy efficient façade retrofit scenarios in Syria.

\section{Post-War Housing Retrofit}

Looking to the damaged buildings due to either wars or natural disasters, it is undeniable that rebuilding is a complex process. By considering the various scale of damage, literature studies emphasize on the context consideration for developing reconstruction scenarios without deciding on demolition as a default [5] [6]. While destruction is a practical scenario when the assessment of structural capacity shows insufficient capacity to resist acceptable limit of damages, housing retrofit for moderately damaged structures minimizes costs and save time when damage can be fixed. Furthermore, the retrofitting process can also be an effective medium for dissemination of best construction practices in the community [6].

Since damage plays an important role in all measures for buildings affected by disasters, retrofit decision-making is first associated with determining the level of risk. Rational decisions have to be made to assess whether the building should be retrofitted or replaced. Hence, conducting a vulnerability assessment is an essential stage before starting retrofitting, which is usually utilized to measure damage and evaluate the scale of needed intervention [6]. Although many tools for vulnerability assessment have been developed, every plan is limited to its contexts and conditions. For example, After the Bam earthquake in Iran in 2003, technical staff devised a rating strategy to assist officials for repair, retrofit or total demolition. It is mainly based on rating the damage for structural and non-structural components by inspection and evaluation of the residential building [5]. A comprehensive methodology for vulnerability assessment for the purpose of retrofitting based on seismic damage were also developed. The assessment includes three main stages [6]. First, the visual assessment should assess the structural deficiencies observed for further investigation. Then, a structural investigation is conducted for sub-structure. Later, the Structural analysis is carried out after completing the investigation to evaluate whether the structural condition is vulnerable or not. If the building is vulnerable, then design of the retrofitting approach should be conducted [7]. The shown chart (Figure 1) summarizes stages of vulnerability assessment based on both strategies. With focus on facade retrofit, the existing façade is constrained by various aspects with regards to the facade conditions [8]. Overall, façade retrofit strategies are classified

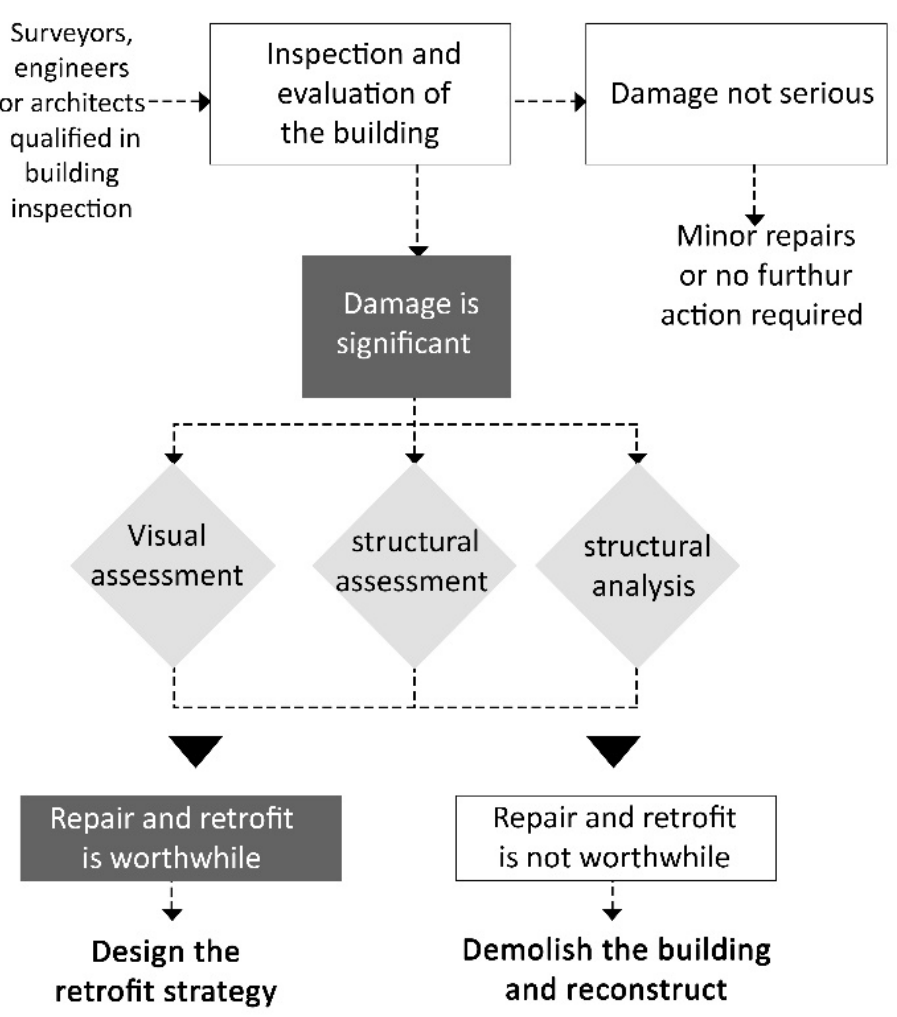

Figure 1. Stages of vulnerability assessment, based on [5] [6] [7]. based on the original construction type, the spacing between the façade layers, and the ventilation system (Table 1).

Table 1. façade retrofit scenarios [8].

\begin{tabular}{lll}
\hline $\mathbf{1}$ & Replacing façade components & A new façade system \\
\hline $\mathbf{2}$ & Adding new components to the façade & Adding shading, space extension \\
\hline $\mathbf{3}$ & Adding new layers to the façade & Insulation, a second skin \\
\hline $\mathbf{4}$ & Replacing the entire façade & A New building is constructed behind \\
\hline
\end{tabular}


In this framework, vulnerability assessment can be reflected within the post-conflict façade retrofit by weighting façade parameters based on its importance with regards to the building use. these include two main parameters. First, Facade geometry and openings includes façade wall geometry, wall slenderness, area of wall opening and misalignment of wall openings. Second, the elements connected with the façade includes conception to roofing and flooring systems [9].

\section{Low Energy Façade Retrofit}

With focus on energy use, retrofitting partially damaged facades is not only legitimate alternatives to full reconstruction but may also represent a significant opportunity to reduce pressure on energy supplies challenges. Furthermore, the Mediterranean climate of Syria allows maximum utilization of passive heating and cooling technologies. Hence, considering energy consumption while retrofitting can meet the user's needs. While the main role of façade can be seen further than meeting the functional requirement, rather providing a comfortable physical and physiological environment. While focusing on providing a comfortable indoor environment thermal, balancing heat losses with heat gains is required to reach thermal comfort [10]. Thermal comfort is defined as 'the condition of mind which expresses satisfaction with the thermal environment [11], The thermal performance of the façade can be evaluated by energy use of the overall building and the estimation of heat loss. However, thermal comfort is affected by façade parameters. These were summarized in the following strategies including, a) openings, b) Shading systems, c) Material and d) orientation [12].

This study investigates the effect of materials on both the overall energy use and thermal comfort. Improving thermal properties of façade components is a basic factor to reach thermal comfort. Through constructions with high thermal mass materials and high level of insulations, the thermal performance of the building fabric can be improved and, which in its turn provides an adequate internal environment [13] [14]. While thermal insulation slows down the rate of heat flow, high thermal mass materials can increase its ability to store heat energy. This study investigates the effect of material choice, insulation and thickness on reducing energy consumption while improve thermal comfort during the housing retrofit process for moderately- damaged buildings.

\section{Methods}

\subsection{Thermal Standards for Comfort in Syria}

The optimum internal conditions for residential buildings are given in the Syrian Code [15]. However, in comparison with CIBSE comfort criteria [16], it could be concluded that CIBSE values are more flexible with bigger range for summer and winter, which can be useful in adapting passive strategies to reduce heating and cooling loads. Aiming naturally ventilated dwelling, occupants seem to adapt to the internal environment according to the outdoor temperature. [16] allows for $\mathrm{A} \pm 3 \mathrm{~K}$ from the comfort temperature for the adaptive approach. The comfort criteria given by the Syrian code is adapted in this study based on the ranges provided in CIBSE in order to respond for the adaptive model design. (Table 2) summarised the comfort criteria in the current Syrian code and the selected values based on the adaptive comfort level.

Table 2. Internal temperatures in residential buildings according to the Syrian Code.

\begin{tabular}{|c|c|c|c|c|}
\hline \multirow{3}{*}{ Space use } & \multicolumn{4}{|c|}{ Dry bulb temperature $\left(C^{0}\right)$} \\
\hline & \multicolumn{2}{|c|}{ Summer } & \multicolumn{2}{|r|}{ Winter } \\
\hline & Syrian code & Adaptive model & Syrian code & Adaptive model \\
\hline Livingroom, bedroom & 22 & $21-28$ & $24-25$ & $19-25$ \\
\hline Corridor, W.C & 18 & $23-31$ & $26-28$ & $15-21$ \\
\hline Baths & 26 & $23-31$ & $26-28$ & $23-29$ \\
\hline Kitchen & 20 & $21-28$ & $24-25$ & $17-23$ \\
\hline
\end{tabular}


In order to achieve these temperatures, understanding climate is crucial step for improving the buildings performance based on the characteristics of the context. Of Damascus city. The city has sunny summers (June to August), and fairly winter (December to February). Summer temperature can reach about $35^{\circ} \mathrm{C}$ while winter temperature can reach $0^{\circ} \mathrm{C}$ as for humidity, the average annual percentage of humidity is $62.0 \%$ [17]. Overall, the degree days shows a larger need for both heating and cooling, since the annual degree days for both summer and winter are convergent, 1206.3 and 1265.3 relatively. (Figure 2) shows the comfort criteria plotted in the psychrometric chart.

\subsection{Case Study Selection}

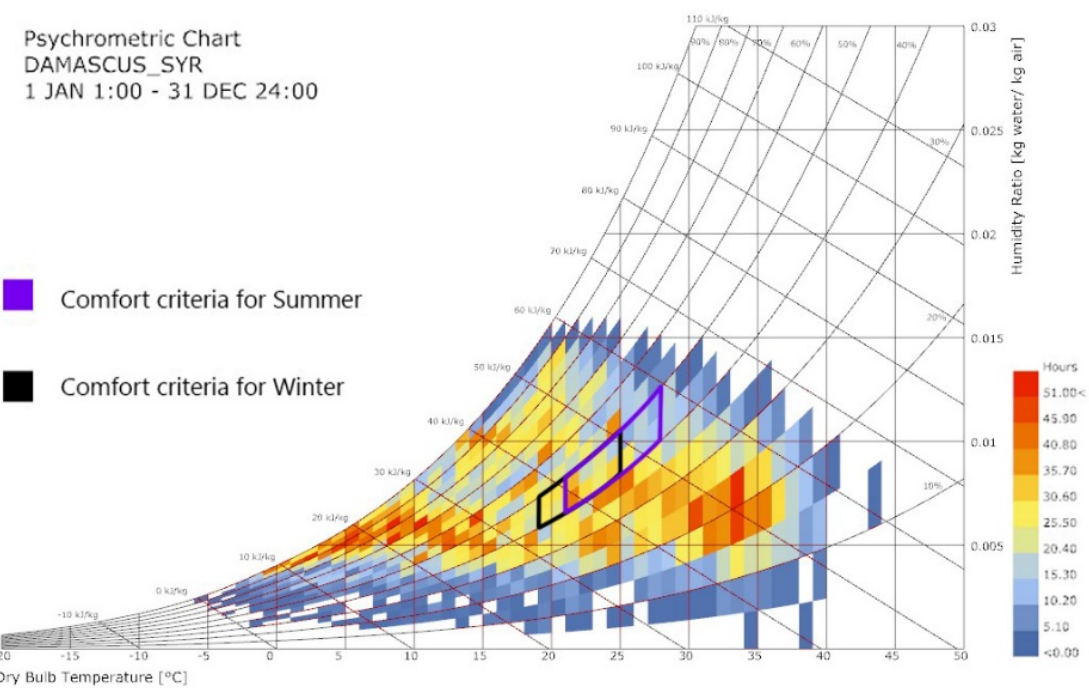

Figure 2. Psychrometric chart based on the weather file.

Based on UNOSAT damage assessment of Syrian cities between 2013 and 2017 [4], Severity is calculated based on density of damaged infrastructure and weighted by a scale of damage based on the following damage classifications, Building Destroyed: all or most of the building structure is collapsed, Building Severely Damaged: a significant part of the building structure is collapsed (30\%- $75 \%$ of structure destroyed), and Building Moderately Damaged: limited damage observed to the building structure (5\%-30\% of structure damaged). The chosen case study is a moderately-damaged four-storey linear residential building with a total site area of $583 \mathrm{~m} 2$. It is located in the north-east suburban area of Damascus city (Eastern Ghouta), where it is the Syria's Second largest region affected by war. It is estimated that moderately damaged buildings in Damascus account for $25.4 \%$ of the total count of damaged structures [4]. Secondly, the urban fabric of Eastern Ghouta is characterised by high density of population with mixture of residential and commercial used settlements. Hence, understanding this context can provide insight into a larger insight to the dwelling's situation in Syria. The ground floor of the selected building is used for commercial purposes while the upper three floors are residential (2 flats in each floor). The flats' area is between $165 \mathrm{~m} 2$ and $130 \mathrm{~m} 2$. Within this building block, the upper three floors for the southern-eastern facade were assessed as a reference unit. Each flat consists of 2 bedrooms, one bathroom and toilet, guestroom, kitchen, living room and two terraces. The main façade is south-east oriented on a 25.5 wide street.

\subsection{Visual and Technical Assessment}
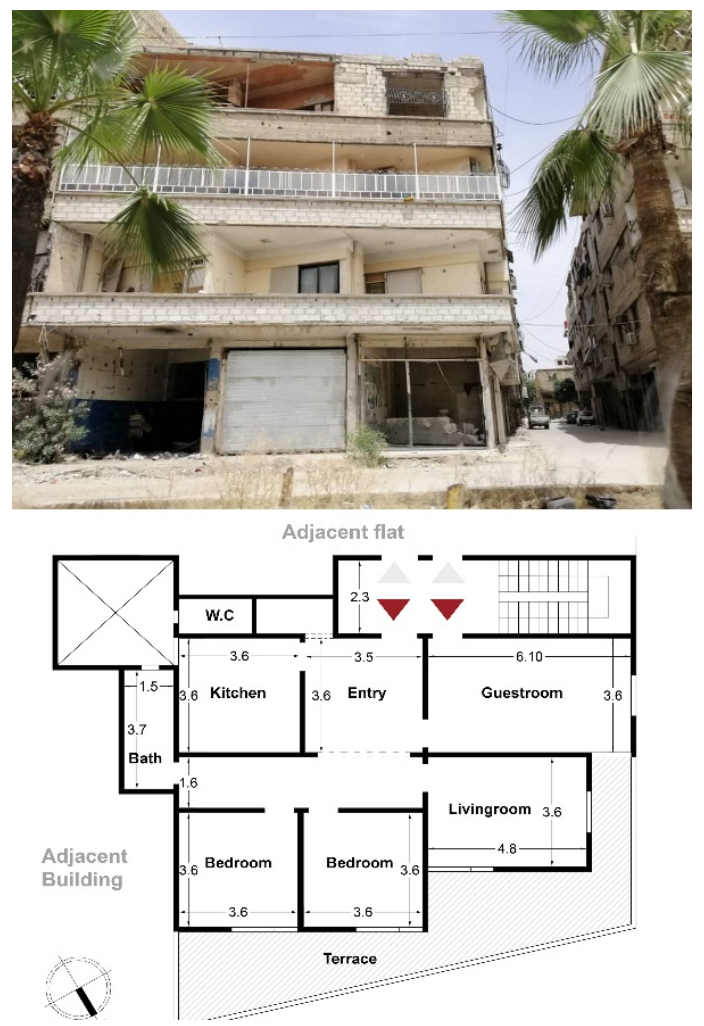

Figure 3. A photograph \& plan of the case study.

The building's current situation was conducted based on the following measures, Rapid visual inspection and assessment, Inspection of cracks and location, Judgment of the construction quality. Inspection of material used and its quality. The assessment of field study, which has taken place in June 2019, is summarised in (Figure 4). 


\subsection{Thermal Assessment}

The building envelope is characterized by the reinforced concrete and uninsulated external walls of $150 \mathrm{~mm}$. the second type refers to the internal walls, which separate the rooms of $120 \mathrm{~mm}$. The openings are composed by single-glazed windows with metallic frame without thermal break; considering the poor thermal performance of this frame its transmittance was rated equal to $5.88 \mathrm{~W} / \mathrm{m} 2 \mathrm{~K}$.

The occupancy, lighting and equipment were modelled based on natural ventilation in dwellings following CIBSE [16]. The base case was modelled with five occupants. The occupancy schedules for weekdays and weekend day (Friday) are selected based on the Syrians behavioural patterns. People in the living room have an activity of $108 \mathrm{~W} / \mathrm{m}^{2}$ while those in bedrooms have $81 \mathrm{~W} / \mathrm{m}^{2}$. An infiltration rate of $0.5 \mathrm{ach}$ throughout the dwelling and the rooms were modelled natural ventilation mode. however, energy pattern in Syrian housing has alternatives of using HVAC systems. The main cooling system relies on electricity by ceiling fans during summer while the heating system is mainly by diesel heaters during winter. Since heating or cooling are more a concern for the bedrooms during night, air-conditioning is installed mostly in bedrooms and turned on if temperature inside above or below the comfort range.

\subsection{Retrofit Scenarios}

The facade characteristics for the wall's material and insulation were presented as design variables. Two different configurations are shown to insulate the current envelope by adding the same insulation in two different thicknesses.

Expanded Polystyrene (EPS) foam for External wall insulation has been selected for optimization because they are the most commonly used high performance materials in the Syrian industry. Based on building performance in previous scenarios, modifying the design by extending spaces and adding terraces to effectively considering the economic aspects of occupant and organise the current random movement of space extension where terraces are existed.

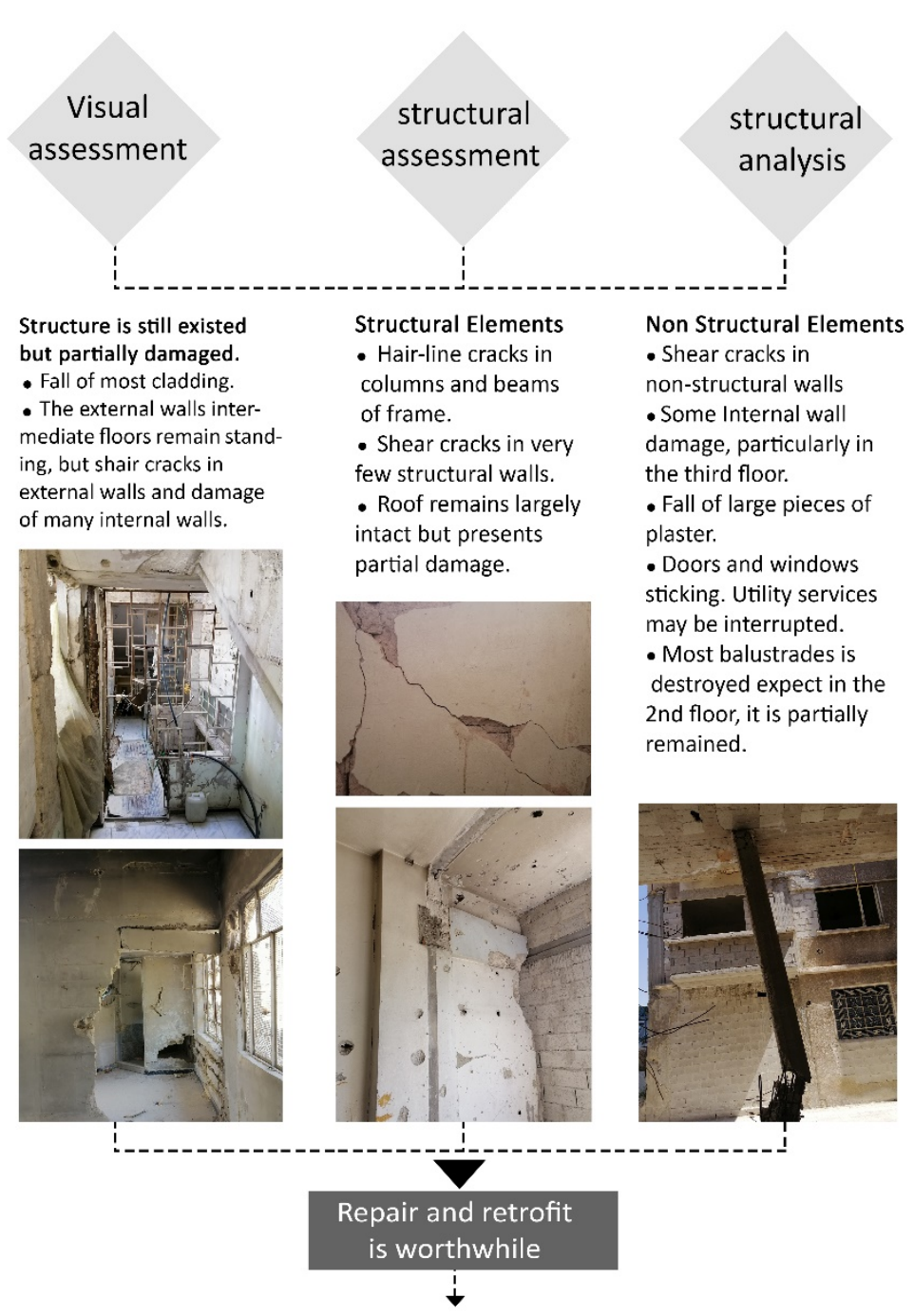

Figure 4. Field study summery of the base case, (June 2019).

Table 3. Thermal properties of building's components

\begin{tabular}{|l|c|l|r|}
\hline Component & Thickness $\mathbf{c m}$ & Material & $\begin{array}{l}\mathbf{U} \text { value } \\
\mathbf{W} / \mathbf{m}^{2} \mathbf{K}\end{array}$ \\
\hline External wall & 15 & Concrete & 2.8 \\
\hline Internal wall & 12 & Concrete & 2.9 \\
\hline Intermediate floor & 30 & Concrete & 2.5 \\
\hline windows & $0.4-0.6$ & Single glass & 5.8 \\
\hline
\end{tabular}


Table 4. Variables of the chosen retrofit scenarios

\begin{tabular}{|c|c|c|c|c|}
\hline $\begin{array}{l}\text { Optimization } \\
\text { parameters }\end{array}$ & Material & $\begin{array}{l}\text { Thickness } \\
\text { mm }\end{array}$ & $\begin{array}{l}\text { Achieved } \\
\text { U-value W/m² K }\end{array}$ & $\begin{array}{c}\text { Syrian Code for building } \\
\text { Benchmarks }\end{array}$ \\
\hline \multicolumn{5}{|l|}{ Scenario 1} \\
\hline Wall Insulation & \multirow{2}{*}{$\begin{array}{r}\text { Expanded } \\
\text { Polystyrene EPS }\end{array}$} & 8 & 0.43 & 0.80 \\
\hline Room insulation & & 6 & 0.32 & 0.50 \\
\hline \multicolumn{5}{|l|}{ Scenario 2} \\
\hline Wall Insulation & \multirow{2}{*}{$\begin{array}{r}\text { Expanded } \\
\text { Polystyrene EPS } \\
\end{array}$} & 12 & 0.21 & 0.80 \\
\hline Room insulation & & 10 & 0.25 & 0.50 \\
\hline \multicolumn{5}{|l|}{ Scenario 3} \\
\hline Wall Construction & Brick & 20 & 0.60 & 0.80 \\
\hline \multicolumn{5}{|l|}{ Scenario 4} \\
\hline Wall Construction & Brick & 20 & 0.60 & 0.80 \\
\hline Wall Insulation & \multirow{2}{*}{$\begin{array}{r}\text { Expanded } \\
\text { Polystyrene EPS }\end{array}$} & 12 & 0.21 & 0.80 \\
\hline Room insulation & & 10 & 0.25 & 0.50 \\
\hline
\end{tabular}

\subsection{Definition of the Modelling Software}

The base case model was modelled using IES-VE software, which is an integrated environmental solution tool that test different design options [18]. The thermal simulation was conducted via Apache, which is the dynamic simulation tool that was used to calculate building's loads, energy and thermal comfort.

\section{Results}

The energy results of the base case showed a considerable difference in heating and cooling load in spite of the relatively similar heating and cooling degree days (Figure 5). This significant difference is due to heat losses through the envelope in winter while shade provided by terraces in summer contributes to the limited solar heat gains, which, in its turn, reduces demand for cooling. However, energy loads were also varied per floor. While cooling loads are slightly higher in the second and third floor (the highest cooling loads is needed in the third floor by $12.3 \mathrm{KWh} / \mathrm{m}^{2}$, heating load shows an opposite trend where the first floor requires the most heating load $\left(28.3 \mathrm{kWh} / \mathrm{m}^{2}\right)$. As a result, the heating demand of $39.9 \mathrm{KWh} / \mathrm{m}^{2}$ is twice higher comparing to cooling load which requires $90.9 \mathrm{kWh} / \mathrm{m}^{2}$. The results of the comfort range in rooms show uncomfortable indoor environment. (Figure 6) shows the incompliance of all rooms with the comfort range as all spaces have $70 \%$ of annual yeas out of comfort zone. First floor has the most significant uncomfortable ranges for winter season while more uncomfortable temperature ranges for summer months occurs in the third floor.

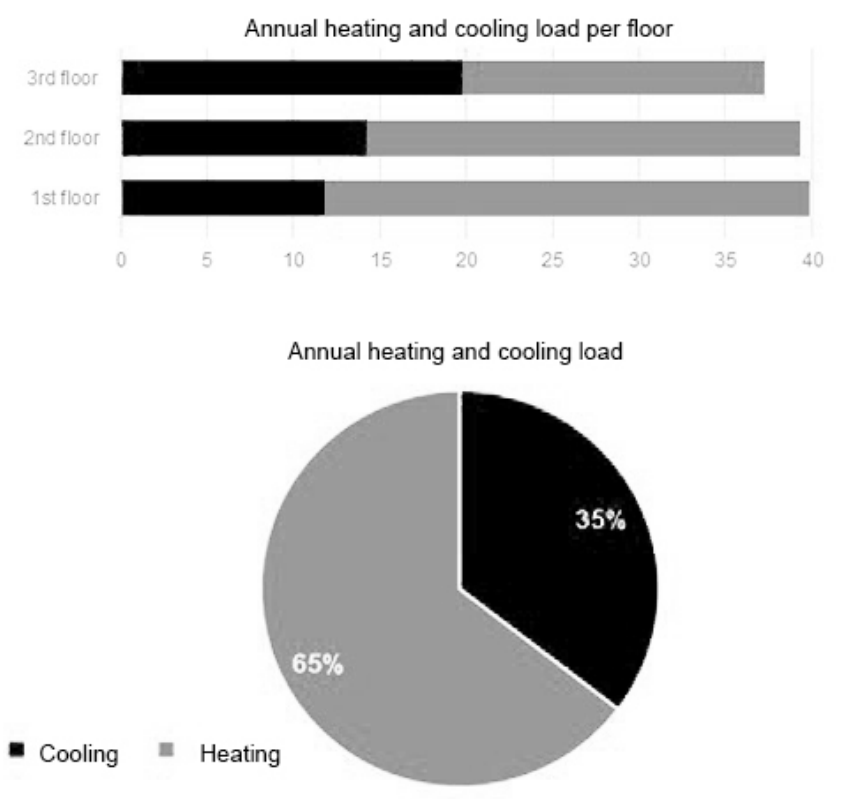

Figure 5. Annual heating and cooling 
By improving the building fabric thermally, the results show a positive impact on reducing energy loads and improving thermal comfort in all naturally ventilated spaces. However, the resulted ranges are varied per each scenario, which gives more flexibility when choosing a retrofit approach. Upgrading existing façade by adding $8 \mathrm{~cm}$ of external insulation, comfort ranges can be improved by $25 \%$ in winter and $30 \%$ in summer while increasing the insulation would improve the indoor temperature by approximately $33 \%$ for winter and summer seasons. These results can be achieved by uninsulated brick envelope, has a considerable effect on reducing internal temperature fluctuations seasonally providing thermal mass. However, the improvement drops to reach cold values of $52 \%$ during winter season. This is because of the impact of terraces on the whole facade that minimized solar gains. Finally, if insulating brick was considered, indoor environment achieves the best results by improving more than half of the occupied hours throughout the year while remarkably reduces both heating and cooling loads.

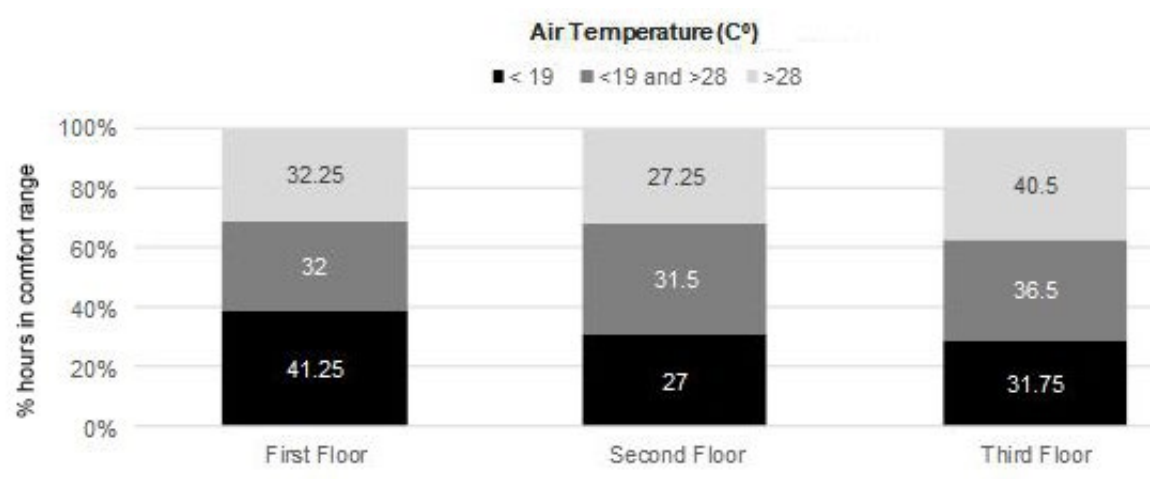

Figure 6. Comfort hours percentage throughout year.

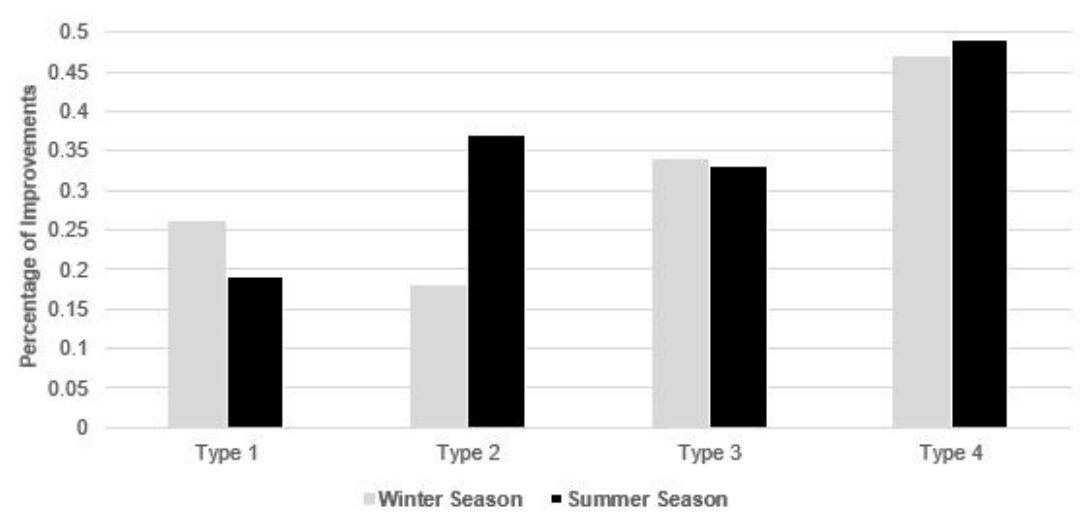

Figure 7. Improvements of annual hours percentage in comfort zone.

Since improving the envelope affects heat gains and losses, all retrofit scenarios showed a reduction in energy consumption, which varied according to the material and insulation applied. As shown in figure 7, with an insulated building with $8 \mathrm{~cm}$ of EPS, heating and cooling loads reach less than $100 \mathrm{kWh} / \mathrm{m} 2$, which contributes to around $15 \%$ of energy savings. Adding a thicker insulation positively results in further energy reduction to achieve around $80 \mathrm{kWh} / \mathrm{m} 2$. It is interesting to mention that choosing another retrofit approach of replacing the material itself could achieve better results than adding external insulation with $12 \mathrm{~cm}$ thickness. This measure can significantly save heating load by $33 \%$ of the annual heating demand. However, adding insulation to the brick wall will significantly reduce heating and cooling demand to reach less than $65 \mathrm{kWh} / \mathrm{m} 2$. As a result, choosing insulated brick for envelope is the optimum solution, which can reduce heating and cooling loads by approximately $40 \%$.

\section{Conclusion}

The aim of the study was to investigate the potential of implementing energy-efficient façade retrofitting in the dwellings affected by the Syrian war. While focusing on a typical residential building in Damascus Outskirts, the study targeted moderately damaged with limited damage observed to 5\%-30\% damage of the building structure. Decision-making in the selection of retrofit scenarios was a result of conducting three stages of vulnerability to measure damage and evaluate the scale of needed intervention. Based on this assessment, multiple retrofit scenarios were developed to improve the building performance by two main objectives, Thermal comfort and energy loads. Two different iterations were shown for one scenario of insulating the current envelope with different insulation thickness. As for the facades that was severely damaged, but the structure is still existed, another scenario was explored by testing the brick performance. It was concluded that aiming 
at improving thermal comfort reduces energy consumption. However, the two objective outcomes are varied. Generally, all results of retrofit scenarios showed that improving the building fabric thermally had a positive impact on the energy loads and thermal comfort both in the air-conditioned bedrooms and naturally ventilated living spaces. However, the resulted ranges are varied per each scenario, which gives more flexibility when choosing the retrofit. Within adding $8 \mathrm{~cm}$ of external insulation, comfort ranges can be improved by $25 \%$ in winter and $30 \%$ in summer while increasing the insulation would improve the indoor temperature by approximately $33 \%$ for winter and summer seasons. Moreover, with regards to energy saving outcomes, it was shown that choosing insulated brick for envelope is the optimum solution, which can significantly reduce heating and cooling loads by $40 \%$. While upgrading walls to the thickest level of insulation can be less efficient with reduction of cooling demand by $20 \%$. However, this study was limited with assessing how the existing building envelope affects thermal comfort and heating and cooling loads, with regards to wall elements and space design without consideration for implementation costs or occupant use of space. In-depth studies could be done in the field of considering energy efficient housing retrofit in the war-affected buildings. Moreover, other studies could investigate considering the social aspect in the process of facade retrofit decision-making.

\section{References}

[1] Butter, David. (2015). Syria's Economy Picking up the Pieces. London: Chatham House, The royal institute of international affairs. Pp 15, 16.

[2] EIA. (2019). International energy data and analysis (Syria). U.S: U.S Energy Information Administration.

[3] Kostial, Jeanne. Gobat, Kristina. (2016). Syria’s Conflict Economy. International Monetary Fund pp 21.

[4] Reach (2019). Syrian Cities Damage Atlas: Thematic assessment of satellite UNOSAT. PP1,2.

[5] Jha, A., Duyne Barenstein, J., Phelps, P. M., Pittet, D. and Sena, S. 2010. Safer Homes, Stronger Communities: A Handbook for Reconstructing after Natural Disasters. Washington, DC: Global Facility for Disaster Risk Reduction, World Bank. PP 166-16

[6] Hari Darshan, Krishna S. Pribadi, Dyah Kusumastuti, Edwin Lim. (2009). Manual on retrofitting of existing vulnerable school buildings. Indonesia: Save the Children, Centre for Disaster Mitigation- Institute of Technology Bandung (CDMITB).

[7] DAVIS, Ian. Alexander, David. (2016). Recovering from disasters. Routledge, London. PP 210-214.

[8] Richards, D. (2015). The importance of façade design. in Burton, S. (ed.) Sustainable Retrofitting of Commercial Buildings: Cool Climates. (Oxon: Routledge) PP 140-160.

[9] Ferreira, T. Vicente, R. Varum, H. (2012). Vulnerability assessment of building aggregates: A macrocosmic approach. Lisbon: 15th World Conference on Earthquake Engineering.

[10] McMullan, Randall. (2002). Environmental Science in Building. 5th. Basingstoke: Palgrave.

[11] ASHRAE. (2017). Standard 55 - Thermal Environmental Conditions for Human Occupancy. Atlanta: ASHRAE.

[12] Hanum Abdullah, Fauziah. Abdul Majid, Noor Hanita. Othman, Rosniza. (2016) international conference on quality of life. Indonesia. Pp 416-423.

[13] Khoukhi, Maatouk. Hassan, Ahmed. Alsaadi, Salah. Abdelbaqi, Shaimaa. (2019) A dynamic thermal response on thermal conductivity at different temperature and moisture levels of EPS insulation. Case Studies in Thermal Engineering,Volume 14.

[14] Escandón, Rocío, Suárez, Rafael. Sendra , Juan José. (2019). Field assessment of thermal comfort conditions and energy performance of social housing: The case of hot summers in the Mediterranean climate. Volume 128. PP 377-392.

[15] Ministry of Local Government. (2008). The Syrian Code for Construction and Thermal Insulation. Arabic Edition. Damascus: Syrian Engineers Association.

[16] CIBSE. (2015). CIBSE Guide A - Environmental design. London: Chartered Institution of Building Services Engineers.

[17] Damascus Weather Data Energy Plus. Accessed January 2020, https://energyplus.net/weatherlocation/europe_wmo_region_6/SYR/SYR_Damascus.400800_IWEC.

[18] IESVE. (2008). In the Future All Buildings Will Be Green, Economic and User Friendly. IESVE. 